\title{
Las hogueras de San Juan en el folklore español
}

\author{
Oscar Javier MENDOZA GARCIA
}

\section{INTRODUCCION}

En todas partes y en cualquier tiempo existe una concepción del fin y del comienzo de un período temporal, fundado en la observación de los ritmos biocósmicos, que se encuadran en un sistema más vasto, el de las purificaciones periódicas y de la regeneración periódica de la vida. "Los cortes del tiempo son ordenados por los rituales que rigen la renovación de las reservas alimentarias; es decir, los rituales que aseguran la continuidad de la vida de la comunidad entera... La adopcion del año solar como unidad de tiempo es de origen egipcio". ${ }^{1)}$ La fiesta de San Juan, veinticuatro de junio, día en que el sol alcanza su máxima altura en el hemisferio norte, ha tenido gran importancia para el hombre de campo europeo. Por San Juan se garantiza la fructificación de las plantas cultivadas y se preservan de enfermedades hombres y bestias por medio de ritos. Fuera también de la cultura europea se ha celebrado esta fiesta con gran esplendor. ${ }^{2)}$ "De las celebraciones solsticiales le viene a este día la fuerza contra las enfermedades, las plagas del campo y los malos espíritus. Este fue el origen de la fiesta que la Iglesia asumió y bautizó con la liturgia de San Juan. Aún quedan aquellos elementos como el fuego como centro del culto solar". ${ }^{3)}$

En Alatoz (Albacete), Carabia (Asturias), Ciudadela (Menorca), Marjaliza (Toledo) y San Juan (Menorca), los vecinos suben a los montes a ver"bailar"al sol. En Mallorca se llama la fiesta del “Sol qui baila”. En Cordovilla (Badajoz), se va a ver la salida del sol a Morrón de Estena (Sierra de San Pedro) y se ve pasar a San Juan Bautista y a los santos Justo y Pastor conduciendo un rebaño de cabras y rodeados de una luz brillante. En Muskiz (Vizcaya), Donibae, el dios sol, es quemado. ${ }^{4}$ Sobre las hogueras de San Juan hay más noticias del Norte de España que del resto. Se aprecia un gran abanico de la fiesta de las hogueras de San Juan, aunque con frecuencia por carecer de detalles sobre costumbres y prácticas particulares 
relacionadas con ellas no se pueden dar datos exclusivos de España. Hubiera sido interesante estudiar qué objetos se queman, cómo se encienden, quiénes deben saltar por encima, etc. No está en nuestra mano hacer una investigación tan prolija por lo que nos centraremos en estudiar la razón de ser y virtudes de estas hogueras en España, en muchas ocasiones coincidentes con otras partes de Europa y fuera de ella.

\section{ANTECEDENTES}

Ś́lo se pudo descubrir el carro como medio de transporte tras haber comprendido el simbolismo de la rueda solar. En principio el carro fue vehículo de las procesiones rituales: paseaban el símbolo del Sol o la imagen del dios solar. "El símbolo, la imagen, el rito, anticipan las aplicaciones utilitarias de un descubrimiento". ${ }^{5)}$ En múltiples niveles, el fuego, la llama, la luz cegadora, el calor interno expresan siempre experiencias espirituales, la incorporación de lo sagrado, la proximidad de Dios. ${ }^{6)}$ El maestro de los herreros de Tanganika oraba así para invocar la protección de las divinidades: "Tú, mi sol, mi luz, cuida de mi".")

"Lo que el calor natural -el del sol o el vientre de la Tierra- hacía madurar lentamente, lo hacía el fuego en un tempo insospechado...Esta es la razón por la cual ya las culturas más arcaicas imaginan al especialista de lo sagrado -el chaman, el hombre-medicina, el mago- como a un señor del fuego". "Producir el fuego en el propio cuerpo es un signo de que se ha trascendido la condicion humana". ${ }^{8)}$

Sobre las hogueras de San Juan "es costumbre digna de que se repare en ella, y tan general, que Simón Mayolo (un erudito italiano del s.XVII) dice de ella así en el coloquio que llamó Juvenilia in nocte Sancti Joannis Baptistae: In plurimis per Germanian vicis et oppidis publici ignes parantur, ad quos utriusque sexus juvenes et senes convenientes choreas cum cantu agunt: multas enim superstitiones observant (Mocedades en la noche de San Juan Bautista: En la mayor parte de toda Alemania y por otras ciudades del mundo se preparan fuegos, en los que jóvenes y mayores de ambos sexos hacen danzas apropiadas con el canto: así observan muchas supersticiones). $Y$ aunque hoy no tienen esas hogueras humo de gentilidad, no dudo es costumbre traducida de ella hasta nuestra edad continuadamente." 9)

La ajustación de estas fiestas a la de San Juan, o el ajuste de San Juan a este día, se hizo quizá porque San Juan está relacionado con el rito del bautismo en que el 
agua y el fuego tienen un papel preponderante. Juan, único santo del que la Iglesia celebra el nacimiento, mengua para que Cristo, Sol invictus (antigua fiesta del solsticio de invierno), crezca. San Juan Bautista unifica bajo una nueva simbología ritos solsticiales de verano en un principio homogéneos, pero que se habían alterado y relacionado con otros por la mezcla de los pueblos. "Esta unificación ha comprendido a otros no solsticiales de verano que tenían una semejanza externa morfológica". ${ }^{10)}$ "No falta quien diga que a este día, muchos siglos antes que el gran Baptista naciese, le llamaban lámpara, con que parece quiso Dios honrar antes el día en que había de nacer aquel lucero, que había de dar testimonio de la luz" ${ }^{11)}$

\section{HOGUERAS EN EL HOGAR}

Fuego, del latín focus, algunas veces vale lo mismo que casa. Según Porfirio era símbolo de la natura divina, y por esta causa se guardaba con tanto cuidado en los templos. Los poetas le llaman Vulcano, herrero, hijo de Juno y Venus. ${ }^{12)}$ Fuego en derecho es hogar, o mejor, la familia y cada una de ellas que habitan en un punto determinado. En Castilla se denomina fumo. En Cataluña focs y fogars. En Galicia las casas que se agrupaban alrededor de la mansión señorial se denominaban fumeiros. ${ }^{13)}$

El hogar constituye el centro más importante de la casa. "En el hogar, el fuego hace invisible, y lleva á los manes de los antepasados, que habitan los sepulcros, la piadosa oblación con que pagan los vivos la más sagrada deuda, y es el conducto por donde llegan hasta ellos sus plegarias". El culto a los lares se enlazaba con íntimo abrazo al culto al fuego, la pira, que fue importado de Asia por los celtíveros. Los lusitanos y gallegos, como los griegos y romanos, incineraban los cadáveres, lujosamente ataviados con torques y brazaletes de oro, y ceremonias especiales. ${ }^{14)}$

En el Nuevo Testamento, el fuego representa la verdad del espíritu: el conocimiento. Jesús dice: "he venido a prender fuego sobre la tierra, iy cuánto desearía que ya estuviera encendido!"(Lc. 12, 49). Se equipara con el conocimiento. Así, Jesús se declara como "luz del mundo"y"luz de la vida"(Jn. 8,12). Es signo del Espíritu Santo (Hch. 2,1-4). El "fuego nuevo" es símbolo de Dios y su amor, del Espíritu Santo y de Jesucristo resucitado. En muchos lugares se observa la piadosa costumbre de encender este fuego nuevo y bendecir el hogar cuando se bendice una casa nuevamente construida. ${ }^{15)}$ "En el Valle de Ollo, Vascongadas, bendecían las 
casas: en una sartén vieja ponían helecho bendecido el día de San Juan del año anterior y lo prendían fuego. Paseaban el humo por todas las habitaciones de la casa para preservarlas de enfermedades". ${ }^{16)}$

El hogar le da a la casa todo su valor y significación. La familia debía mantener constantemente viva la llama del hogar, en la cual palpitaba el espíritu de la divinidad, "agni". En algunas inscripciones, al lado de la dedicación ritual a los manes, descubrimos el signo oriental llamado svasti 円 , que fue el símbolo del sol y del fuego. El fuego sagrado del hogar, la vesta de los latinos, estia de los griegos, era invocado como una divinidad tutelar, medianera entre la tierra y el cielo, y la familia se la hacía propicia con ofrendas. De los primitivos arios del Asia Central recibieron los persas, griegos, romanos y también los españoles el culto al fuego sagrado del hogar. Cada pueblo lo heredó colateralmente de sus respectivos progenitores; no se diga que los españoles lo recibieron de los romanos, pues cuando éstos entraron en la Península Ibérica este culto al fuego del hogar estaba ya en desuso entre ellos por lo que lo debieron contemplar como una novedad. ${ }^{17)}$

El fuego doméstico tiene fuerza sagrada que da vida. Por esto debe permanecer siempre encendido. El origen y conservación del fuego son misterios de Dios. Los ritos y aplicaciones prácticas son de los hombres. El momento de cubrir el fuego con ceniza al final de la jornada para su conservación estaba rodeado de oraciones y ritos que lo convertían en motivo de culto. Se hacía la señal de la cruz sobre la ceniza al tiempo que se decía una oración. Se pensaba que por la noche bajaba Dios, la Virgen, los ángeles o los antepasados. En Pipaón, en 1976, se encontró una talla de madera con forma de tres llamas, idolillo con el que se daba culto al fuego. ${ }^{18)} \mathrm{El}$ fuego sagrado del hogar tenía la virtud de inmunizar la vivienda contra los poderes nocivos. El terreno bajo el alero tenía también este privilegio. Después la teja paś a ser símbolo de la vivienda y sus defensas. La madre que tras el parto estaba en cuarentena debía salir con una teja en la cabeza. La teja pasó del derecho consuetudinario al Derecho Foral de Vizcaya y al Fuero de Ayala como signo de protección. ${ }^{19)}$

\section{HOGUERAS FUERA DEL HOGAR}

En la antigüedad todos los festejos públicos tenían carácter religioso y las luminaciones y hogueras solían coincidir con la celebración de algún misterio o 
alguna solemnidad. "En Grecia en la fiesta de la vendimia se dedicaba a Baco una gran hoguera y se daba vino en abundancia a los transeúntes. Entre los romanos había antorchas en las fiestas de Ceres. Servio Tulio dispuso que en la época de la siembra, cada ciudad de Italia tuviese un día de descanso y prendiese fuego en la plaza pública. Tal fiesta era la Sementera o Panganalia. Era costumbre saltarla tres veces. Tambien hacían hogueras en las fiestas de los Juegos seculares. ${ }^{20)}$

Se ha perpetuado en la Península Ibérica la costumbre de solemnizar con las hogueras las festividades principales de cada pueblo, los días que solemnizaba la Iglesia Católica, en especial las fiestas patronales de cada pueblo. Todos los años, en el solsticio de verano, se hacía la purificación del fuego con gran solemnidad. La renovación del fuego y otras ceremonias de la raza aria conservan aún importantes reliquias en España. Herodoto (liv. IV, c. 138), afirma que todas las tribus libias, y por tanto la Península Ibérica, rendían culto e inmolaban víctimas al Sol y a la Luna. Estas eran las deidades supremas de caldeos y asyrios. "Tanto los íberos como los libios traían de allí, al menos en parte, su descendencia". ${ }^{21)}$

Después estos ritos se han cristianizado. Antiguas plegarias dirigidas a "Joanes" le identifican con el sol. "Hasta mañana, Juan; ven mañana con buena suerte". La custodia del Santísimo sacramento se llama en Varcarlos "santo Sol".22) "El cristianismo conservó esta práctica en el día de San Pedro y sobre todo en San Juan. Al generalizarse el uso de la pólvora las hogueras de San Juan se sustituyeron por fuegos artificiales". 23) "Por Navidad en la chapa (fogón), y por San Juan en la plaza" es un refrán de Urdiáin, en Vascongadas. El fuego solsticial tiene su continuidad en el fogón doméstico. Un poco de fuego de la cocina se arrojaba a la calle y después se recogían brasas de la hoguera de la calle y se metía en el hogar. Así se echaban los males y se traía la bendición de Dios: es el rito de la renovación del fuego del hogar. ${ }^{24)}$ En casi toda la campiña catalana se hacen o se hacían hogueras familiares y hogueras colectivas; unas de tipo familiar, las otras encendidas ante la iglesia o el ayuntamiento. "Hay masías aisladas que encienden hasta cuatro, una a cada lado o ángulo de la casa, para que, así, ésta no pueda ser embrujada, ni robada, ni objeto de otros maleficios. Los pastores, los carboneros, los guardabosques, etc., las encienden a la entrada de sus cabañas con el mismo fin". ${ }^{25)}$

Las danzas en torno a la hoguera son alegres. Saltan sobre ellas los jóvenes descalzos. A la mañana siguiente marchan a tomar chocolate y churros al campo. ${ }^{26)}$ 
Una publicación anónima, refiriéndose a Castilla en general, afirma que "suelen mozos y mozas trasladarse en la noche víspera de San Juan a algún paraje próximo al pueblo y allí toman chocolate al salir el sol"."27) "Por regozijo se hazen hogueras en la fiesta de San Juan Baptista y otros santos y en las alegrías por nacimientos de príncipes y por otras causas. El saltar por encima de las hogueras se haze agora con simplicidad; pero antiguamente tenía cierto género de superstición y tuvo origen de los caldeos según escriven autores graves. Llevadme cavallera, y sea a la hoguera; esto dixo una hechizera, llevándola a quemar". ${ }^{28)}$ Estas hogueras se conservaban en Espana toda la noche; "the children leap over them in a certain rhythmical way which is said to resemble the ancient dances" ${ }^{29)}$ La hoguera nocturna ha sido siempre en España signo de fiesta, bien fuera civil o religiosa. Lo que diferencia las hogueras de San Juan de las de otras festividades es que las de San Juan son generales de todos los lugares y son propias de la víspera de ese día, mientras que las de otras fiestas son particulares de algún lugar y propias de fechas distintas. Hay también otro tipo de hogueras de alegría por algún acontecimiento político o histórico, como las que se hicieron en Lérida para festejar la toma de Granada por los Reyes Católicos. ${ }^{30)}$

\section{VIRTUDES DE LAS HOGUERAS DE SAN JUAN}

\section{El fuego como protector y destructor}

Desde siempre el ser humano ha desarrollado una fuerte idolatría por el fuego y por su contradictorio simbolismo, ya que puede significar tanto el Bien como el Mal. ${ }^{31)}$ El fuego en el Antiguo Testamento es ambivalente: protector-destructor. Yhwh es muralla de fuego protectora del pueblo y a la vez destructora de los enemigos de Israel. "Yhwh es fuego en medio del pueblo, una especie de hogar teológico que procura calor, seguridad y bienestar, la llama del hogar de los israelitas. Sin embargo, de estos depende el que prenda o no, en ellos de forma destructora". ${ }^{32)}$

Jesús se nos presenta en muchos cuentos populares europeos como el señor del fuego por excelencia. El señor del fuego, como el mismo fuego, son susceptibles de diferentes valoraciones: pueden tener carácter divino o demoníaco. Existe un fuego celeste, que fluye ante el trono de Dios, mientras en la Gehena quema el fuego infernal. "En el folklore religioso y laico de la Edad Media lo mismo Jesús que 
el Diablo aparecen como señores del fuego" ${ }^{33)} \mathrm{El}$ dominio del fuego, común al mago, al chamán y al herrero, fue considerado en el folklore cristiano como obra diabólica; una de las imágenes populares más frecuentes presenta al Diablo arrojando llamas por la boca. En las civilizaciones clásicas, el fuego constituía un elemento sagrado, en la Edad Media adquirió un matiz purificador (purgatorium: lugar de purificación), puesto que se consideraba que aniquilaba, o al menos ahuyentaba a los malos espíritus causantes, según creencias y supersticiones, de todas las desgracias acaecidas sobre personas o animales. En la actualidad, ha quedado más bien como mera diversión.

\section{Poder purificador $y$ vivificante del fuego}

"Fire is seen also as a means of purification (the refine 's fire) and that view is extented, especially in cultures that employ cremation, to the notion of fire as a means of rejuvenation or of gaining immortality" ${ }^{34)}$ Cuentos del folklore europeo tienen reminiscencias rituales en las que "el fuego ocupaba el papel de prueba de iniciación y, a la vez, de agente de purificación y transmutación (el bautismo de fuego en el cristianismo primitivo y en el gnosticismo representa uno de los ejemplos más elaborados de este argumento)". ${ }^{35)}$ "Por entender los antiguos que pasando por el fuego se limpiaban de los pecados, les llamaron a estas fiestas lustraciones, y dice Columela (De re rustica, lib.2, cap.28) que se hacían entre otros sacrificios por las sementeras y que era envejecida costumbre... despues de haber hecho muchas ceremonias a su usanza y dicho ciertas oraciones a la diosa Palas y a Fauno, deidades de los campos, encendían las hogueras de heno y saltaban por cima de ellas. Ovidio, 4 Fastos... Persuadianse que esta ceremonia, no sólo limpiaba al que la hacía, como es cierto que el fuego purga y cuece el metal, sino que también limpiaba su ganado...Aún duró mucho tiempo esta persuasión general de que el fuego purgaba y limpiaba las cosas polutas y manchadas". ${ }^{36)}$ Efectos saludables del fuego ritual del culto al Sol eran: -Saltar sobre la hoguera: remedio medicinal. -La llama de las gavillas: supresión de plagas y animales dañinos. -El humo de las hierbas: purifica la vivienda. -La ceniza sobre la sementera: acción benéfica. ${ }^{37)}$

El fuego ha quedado como centro del culto solar. Aún en los Pirineos es saludado con estruendo de salvas, cohetes y tiros de escopeta. También los tiros servían para alejar las tormentas. En Arraazu los mozos y hombres repicaban las 
campanas mientras duraban las hogueras. Las romerías duraban hasta la mañana siguiente. Había danzas con letra y música alusivas a San Juan. ${ }^{38)}$ En la Costa Mediterránea, es en Alicante donde más importancia social han adquirido las fogatas de San Juan desde su oficialización en 1928. En un principio eran una imitación a Valencia, cuyas fallas son fiestas de acogida a la primavera. Hoy se intenta acercar el arte al pueblo y que éste participe (hogueras experimentales). ${ }^{39)}$ Se repiten ancestrales ritos y ceremonias bajo el signo del jolgorio y la diversión pero bajo el mismo signo purificador del fuego. ${ }^{40)}$ También en Murcia quemaban en las hogueras de San Juan muñecos que llamaban Juanes y Juanas mientras se encendían fuegos de artificio.

\section{El paso por el fuego: rito purificatorio}

"Entre los pecados que la Escriptura cuenta que hizo Manasés, fue uno hacer que sus hijos pasasen por el fuego. Paralipom. lib.2, cap.23" (Crónicas, 33, 6). La misma historia se lee en II Reyes, 21, 6 y Ezequiel 20, 26. Llegó esta idolatría de inmolar los propios hijos en el fuego hasta los tiempos de la Iglesia cristiana. ${ }^{41)}$

En San Pedro Manrique, Soria, se celebra un rito particular con la hoguera de San Juan. Los vecinos pasan descalzos por encima de una capa de tizones de un metro y medio de longitud y otro metro de anchura por ocho o diez centímetros de espesor. Creen los sampedranos que sólo ellos pueden pisar el fuego sin quemarse. "El pueblo ibero, agolpado rugiente alrededor del Fuego, cumple una vez más con los ritos solsticiales de la fertilidad en honor de la Madre Tierra, del Fuego, de la Luz, del Sol...El fundamento primitivo de las hogueras de San Juan era preparar el cuerpo y el alma para los ritos penitenciales con objeto de recibir luego, purificados, los primeros rayos del Dios Sol en el día sagrado". ${ }^{42)}$ Afirma el insigne Julio Caro que los sorianos de esta aldea y sus vecinas poseen un espíritu algo más jocundo y dionisíaco que sus paisanos de más al sur, quizá debido a su vecindad y relación con La Rioja, donde hay campos feraces y el carácter de los campesinos es pintorescamente bullicioso y violento. "Parece que el acto se lleva a cabo en la primera juventud, o cuando se hacen promesas por enfermedad de parientes u otras causas". ${ }^{43)}$ Aunque para Caro Baroja la fiesta es muy compleja pues está unida al papel de las móndidas, no llega a explicar que la relación está en que también el rito de las móndidas es purificatorio. Su nombre viene de "mundus": limpio, sin pecado, 
virgen o purificado. Estas móndidas, llevan sobre sus cabezas unos cestillos de mimbre en cuyo interior hay rosas, pan y tres arbujuelos (ramitas tiernas de frutal recubiertas con una capa de pan cocido, tintado de amarillo con azafrán). Esta misma ofrenda de pan y arbujuelos era llamada móndida, quizá resto del fruto ofrecido al Sol por los celtíveros.

La hoguera responde a una conducta de exhibición y espíritu desafiante. Así en Idiazabal se oye "uno de aquí a dos de ahí, iven si vales! (si te atreves). ${ }^{44)}$ La finalidad consistía en mostrar una proximidad especial a Dios y presentar las pruebas de que una fe firme puede dominar incluso las leyes de la naturaleza. ${ }^{45)} \mathrm{Los}$ chamanes y hechiceros, "dueños del fuego", se tragan carbones encendidos, tocan hierros al rojo o andan sobre el fuego. "El chamán y el yogi han superado la condición humana y participan ya de la condición propia de los espíritus" ${ }^{46)}$ Antes pasaban el ganado de toda clase por encima de los restos de la hoguera para librarlo de daños y maleficios. Incluso creen en Galicia que preserva a los animales del muermo y otros males el aspirar el humo de las fogatas. ${ }^{47)}$ Los ritos de contenido naturalista subyacen bajo costumbres piadosas de manifestación religiosa. Con el fuego tenemos en cuenta el poder vivificante del sol. El calor es vida, el frío muerte; la luz es positiva, la oscuridad, negativa. Y es así cómo el fuego se ha encendido en las tumbas tratando de enlazar la vida con el calor. La madre decía al tirar el diente de leche de la criatura al fuego: "Tori zarra eta ekatzu berria"(toma el viejo y dame el nuevo). ${ }^{48)}$ Con motivo de la hierofanía del Sol en el día de su máximo esplendor se opera una transformación del cosmos. "A las doce de la noche se renueva la naturaleza, se neutralizan los maleficios y se curan las enfermedades, en virtud de unos ritos que se repiten en ese preciso momento. Equivale a una nueva creación". ${ }^{49)}$ Ese es el significado propio de regeneración: nuevo nacimiento. El $a k i t u$, ceremonial del Año Nuevo babilónico, el oficiante invocaba a Marduk para "que pueda seguir venciendo a Tiamat (el monstruo marino) y acortar sus días" como hizo in illo tempore y que puso final al caos. ${ }^{50)}$

\section{Fertilidad y buena cosecha}

La fiesta del Sol o de San Juan ha tenido siempre una relación directa con la fertilidad, con la continuidad de la vida. Era un canto a la procreación y purificación de los seres vivientes. La más solemne fiesta de los guanches al Sol era la del 
solsticio boreal. Como propiciación se inmolaban varias cabras con objeto de dedicar un gran banquete al Sol (Achamán), para que enviara la lluvia sobre los campos y los hiciera fértiles. ${ }^{51)}$ Las celebraciones solsticiales se proyectan a todo el año, $o$ al ciclo de los frutos del campo. Hay una bendicion implícita para la semilla, en la ceniza de las hogueras de San Juan que se guarda y se mezcla al abono del trigo. ${ }^{52)}$ Por medio de ritos en este día, se garantiza la fructificación de las plantas. Hay pueblos en que rocían los campos, o el mar para atraer la pesca, como en Bermeo. "El paso por el fuego asegura una abundante cosecha en los campos sembrados y los frutales y toda clase de plantas" ${ }^{53)}$ En Cintruénigo, Navarra, la ofrenda que se hace al santo es una ofrenda típica de agricultores. Seguiremos viendo esta virtud mezclada con la curación.

\section{Protección y curación}

Sol, agua, y vegetación se mezclan en los ritos para evitar peligros. "Las hierbas y ramas bendecidas en la mañana de San Juan, una vez cocidas, han tenido propiedades curativas. Con su agua se lavaba el cuerpo del fallecido, y quemadas en el fuego del hogar o depositadas sus cenizas junto a la puerta de entrada a casa alejaban el peligro del rayo. Al igual que el espino, el fresno, el nogal o el laurel colocados en la mañana de San Juan en la puerta de acceso al caserío evitan el rayo y el pedrisco" ${ }^{54)}$ "Chegamos 6 solsticio de verán e cerrámo-lo ciclo do lume cunna festa solar na que as fogatas ou cacharelas sobre as que hai que brincar para escorrenta-los perigos son a orxía do lume que Galicia celebra. A Igrexa adicon esta festa a san Xoán, o Bautista, e así auga e lume constiúen os dons elementos antagónicos e harmonizados" (Llegamos al solsticio de verano y cerramos el ciclo de la luz con la fiesta solar en que hacen fogatas y hogueras de San Juan, sobre las que hay que saltar para ahuyentar los peligros, que es una gran fiesta de la luz que celebra Galicia. La lglesia dedica esta fiesta a San Juan, el Bautista, y así agua y luz consituyen los dones, elementos antagónicos y armonizados). ${ }^{55)}$ Se ponen tizones encendidos en el interior de un recipiente y se le añaden tres clases de hierbas bendecidas el día de San Juan. Se aplica el humo a la parte enferma, al tiempo que se santigua con dos hojas de laurel cruzadas en forma de cruz, invocando a San Juan y al Espíritu Santo para que lo cure. ${ }^{56)}$

Como se ve en Zaldíbar y Arrazola de Vizcaya se pide de todo: "sarna 
fuera"encabeza la lista. Las cosechas de maíz y trigo compiten con las de pan y vino. Hay para los ratones y alimañas del campo y para los propios piojos. Se reclama la ruina del projimo. En Oiz, Navarra, se queman crucecitas de palo y ramos de laurel que habían sido bendecidos el año anterior y habían estado colocados en los campos. Saltan la hoguera gritando: "Sarna fuera ona barrena eta gaixtoa kanpora" (Sarna fuera: lo bueno dentro y lo malo fuera). ${ }^{57)}$ En Larraun, Navarra, las cenizas de las hogueras se guardan para curar los granos a los niños. Tanto ancianos como jóvenes saltan tres veces diciendo "sarna fuera" o "sarna a Guipúzcoa". El conflicto familiar se hace internacional en Valcarlos: "iSarnafera, lo bueno para adentro, lo malo para fuera! El maíz y el trigo para España, la tiña para Francia." 58 )

En Galicia preserva de determinadas enfermedades a los que las "salvan" (saltan) en "pelico" (en cueros), y debiendo saltar determinado número de veces, impares siempre, una vez de un lado y otra de otro. Al hacerlo suelen cantar:"Salto por en riba do lume do San Xoan, pra que me non trabe nin cobra nin can" ("Salto por encima del fuego de San Juan para que no me muerda ni culebra ni perro"). Creen que el salto es remedio eficaz, sobre todo, para las dolencias de la piel y para evitar contratiempos. Si es una criatura la enferma, la pasan desnuda. La joven que salta la hoguera sin tocar la llama creen que tiene la seguridad de que ha de casarse dentro del año... si no, queda soltera. ${ }^{59)}$

En los pueblos más pegados a las altas cumbres pirenaicas es donde más manifestaciones ha tenido el rito de saltar las hogueras en Cataluña. En Sarroca de Bellera saltan nueve veces la hoguera para "desambromás" (quitarse los males del cuerpo). La ceniza de las hogueras se conservaba pues cura callos, grietas, erupciones y enfermedades de la piel en general. En Urgel se asa una cabeza de ajo en el rescoldo y se come como preventivo contra la sarna. Se cree también que esta ceniza mata los insectos y favorece la cosecha de los campos. ${ }^{60)}$ Quizá por eso es por lo que los hombres con el alcalde a la cabeza van al monte, encienden cada uno su falla (tea grande), una rama de pino resinosa, y las depositan en la fogata del pueblo. Esto, con pequeñas variantes, se ve en Lérida y en el alto pirineo aragonés. Isil, Lérida, es uno de los pueblos más conocidos por esta bajada del monte con abetos encendidos. Estos dimonis crean un espectáculo que ya se celebraba en el siglo XII. ${ }^{61)}$ 


\section{Ahuyentan las brujas y otros males}

Este humo ahuyenta las brujas y espíritus malos en Viana del Bollo, Orense. ${ }^{62)}$ En Cegama, Guipúzcoa, los niños, formando corros se divierten dando saltos alrededor de las hogueras que encienden en las proximidades de los caseríos. "Cuando está a punto de apagarse la hoguera, encienden en ella un pellejo viejo; uno de los muchachos lo coge en la punta de un palo y echa a correr..."; los demás le siguen cantando una canción en que se pide la quema de las brujas y espíritus malos. En la plaza del pueblo se enciende una gran hoguera también, y se practican los mismos ritos que en los caseríos. ${ }^{63)}$ En Elcano, Vascongadas, los chicos encendían pequeñas hogueras en las huertas y con manojos de trigo circulaban alrededor de la fogata, cantando: "San Juan, San Juan, un huevo en el regazo, otro en el seno. iQuema, quema a las brujas y a los ladrones! iGuarda, guarda los trigos y los maíces! Viva San Juan, mañana es san Juan”. También recogida en Zaldíbar y Arrazola (Vizcaya). ${ }^{64)}$ En Amorebieta, Vizcaya, se queman hojas de laurel bendecidas el día tres de mayo o el Domingo de Ramos; en Mandata, hojas de laurel y variedad de flores recogidas el mismo día. En Andoaín, Guipúzcoa, se encienden hogueras, al son de las campanas de la iglesia, en cada casa. Se queman espinos y las malezas que crecen en las márgenes de los caminos, que los chicos se encargan de cortar. En la plaza se enciende una mucho mayor, en la que se quema un carro de leña. En la calle se queman, además, con preferencia, pellejos viejos. En Larrabezaua, Vizcaya, se queman los restos de las gavillas de paja, restos de zapatos y algunas alpargatas viejas. Esta práctica es para ahuyentar a los espíritus dañinos. En este pueblo se dice que es para ahuyentar de la casa las comadrejas. ${ }^{65}$

Las brujas son una preocupación constante. En Valcarlos se oye: "iYa llega San Juan, hemos perdido el miedo a las brujas! Si se ha perdido, que se pierda; que no aparezca nunca". En Mudaca queman una bruja vestida de señora mayor y que va sobre una escoba y lleva un gato en la punta. Lleva un búho sobre los riñones. Es paseada al son del txistu y comparsa de jóvenes que bailan alrededor. ${ }^{66)}$ Este ritual que se repite en tantos pueblos de Vascongadas se ha hecho internacionalmente conocido, siendo visitado por miles de extranjeros. ${ }^{67)}$

\section{CONCLUSION}

Las fiestas del solsticio de verano, así como las de mayo, son fiestas de 
exaltación de la vida de hombres, animales y plantas. Se trata de expresar una concepción del mundo vitalista. En mayo también era adorada el agua. Como objeto de culto naturalista queda el sol que con su fuerza es el elemento fundamental y típico de esta fiesta de San Juan. El origen solar de las fiestas de San Juan queda plenamente probado por muchos autores. Las hogueras son representaciones del sol (divinidad) que se encienden en fiestas de primavera pero más generalmente en la fiesta de San Juan. El culto al sol, mezclado con el culto al agua, ambos elementos principios de la vegetación y de la vida en general, producen una serie de prácticas como colectar y desparramar hierbas y ramas, de las que no nos hemos ocupado ahora. Son prácticas que tienen por objeto la conservación de la vida en orden a asegurar la generación. También se da aquí el sacrificio del gallo, entre otros, que tratamos como más propio del Carnaval. ${ }^{68)}$

Las hogueras son acompañadas por gritos, cantos y paseos por los campos de los mozos y chicos con antorchas, luminarias y pellejos encendidos, que recuerdan la época de Navidad y, especialmente, de primeros de año. ${ }^{69)}$ Saltando sobre las hogueras, aspirando su humo, danzando a su alrededor, pasando a niños y animales sobre ellas, se preservan de males y enfermedades (de la piel sobre todo) y se curan otras; se evitan las tempestades y se asegura la cosecha; ahuyentan a los malos (brujas) y atrae el bien. Se expresa también una madurez física y mental suprahumana.

A pesar de que el folklore popular tradicional ha experimentado una gran decadencia, las hogueras de San Juan por ser lo más representativo y llamativo de esta fiesta se ha salvado de la quema. Con la democracia, por otra parte, asistimos en España a una mayor secularización de las fiestas populares que está haciendo que resurjan estos ritos ancestrales que un día y por siglos la Iglesia cristianizó. Pueblos y ciudades buscando sus raíces están haciendo un gran esfuerzo de recuperación de este rito milenario en pro de unidad, espíritu de convivencia y tolerancia y también para poder mostrar su propia identidad. Buscar el porqué y el fundamento de este rito de San Juan en España ha sido nuestro propósito en este pequeño trabajo. Hemos visto que no podemos quedarnos en hacer una mera referencia a las fiestas romanas o griegas como si las de España fueran una copia evolucionada, idea que han defendido ciertos autores. Tampoco creemos sea justo meter en el mismo saco a este rito de las hogueras de San Juan con otros de otras épocas del año y mucho 
menos con otros de otras latitudes del mundo. Puede que tengan una función originaria común pero ha sido preciso estudiar las intenciones concretas de esta manifestación festiva en diversos puntos y momentos históricos de los pueblos de España para expresar la razón de ser que las ha dado vida y otras razones que las ha hecho perdurables hasta hoy. Visto desde el punto de vista del ciclo agrícola, las hogueras de San Juan se colocan entre las fiestas de invierno, fiesta de siembra, y las de verano, fiestas de recolección. Es el tiempo en que la mies y las plantas en general están rebosantes de vida y se desea que esta vida sea transmitida a los animales y en última instancia al hombre.

\section{NOTAS}

1) Mircea Eliade, El mito del eterno retorno, Madrid, Alianza Editorial, 1995, p.53-54.

2) Julio Caro Baroja, Ritos y mitos equivocos, Madrid, Itsmo, 1989, p.111.

3) José María Satrústegi, Mitos y creencias, San Sebastián, Sendoa, 1983, p.83.

4) Pedro Gil Murcia, El folklore de San Juan, costumbres y tradiciones, Ayuntamiento de Alcobendas, Centro de Actividades Tradicionales de Alcobendas, 1992, p.9.

5) Mircea Eliade, Herreros y alquimistas, Madrid, Alianza Editorial, 1996, p.24.

6) Mircea Eliade, Herreros y alquimistas, p.151.

7) Mircea Eliade, Herreros y alquimistas, p.56.

8) Mircea Eliade, Herreros y alquimistas, p.72.

9) Rodrigo Caro, Dias geniales o lúdicros, II, Madrid: Espasa-Calpe, 1978, p.51.

10) Julio Caro Baroja, La estación del amor, Madrid, Taurus, 1979, p.119.

11) Rodrigo Caro, Días geniales o lúdicros, II, p.55.

12) Sebastián de Cobarrubias Orozco, Tesoro de la lengua castellana o española, Madrid, Castalia, 1994, p.562.

13) Enciclopedia Universal Ilustrada Espasa Calpe, t. XXIV, Madrid,1984, p.1446.

14) Juaquín Costa, La religión de los celtiveros y su organización política y civil, t. XII de la Biblioteca económica 2a. edición, Madrid, Biblioteca Costa, 1917, p.57.

15) Kellner-Villaescusa, El ã̃o eclesiástico, Barcelona, Cath. Encicl. (New York) 1909, "fire".

16) José María Satrústegi, Mitos y creencias, p.79.

17) Juaquín Costa, La religión de los celtiveros y su organización política y civil, pp.58-59.

18) José María Satrústegi, Mitos y creencias, p.90.

19) Adrián Celaya Ibarra, El derecho foral de Vizcaya en la actualidad, Bilbao, La gran enciclopedia vasca (Zalla Vizcaya), 1970, p.98.

20) Solans, Manual litúrgico, Barcelona, 1905, pp.40-41. 
21) Juaquín Costa, La religión de los celtiveros y su organización politica y civil, p.125.

22) José María Satrústegi, Mitos y creencias, pp.60-61.

23) Solans, Manual litúrgico, p.41.

24) José María Satrústegi, Mitos y creencias, pp.79-90.

25) Julio Caro Baroja, La estación del amor, p.146.

26) Luisa Yravedra y Esperanza Rubio, Leyendas y tradiciones de la Rioja, Instituto de estudios riojanos, 1980, p.91. Es esta una tradición que perdura en casi todos los pueblos de La Rioja, incluso en la capital, Logroño, según me narra mi madre Milagros García que ella misma ha presenciado. Son típicas las vueltas, baile de San Juan, cogidos de la mano, en la plaza de Nájera y Huércanos (La Rioja).

27) Julio Caro Baroja, La estación del amor, p.137. Ver Sección de folklore de España, t. XXI de la Enciclopedia uniwersal ilustrada europeo-americana, Barcelona, 1923, p.474.

28) Sebastián de Cobarrubias Orozco, Tesoro de la lengua castellana o española; ver "Hoguera" en la edi. Martín de Riquer, p.693 a.; de la de 1611 fol.474 r., edi. en 1995.

29) James George Frazer, The Golden Bough. A study in Magic and Religion $3^{\text {rd }}$ edi. London, The Macmillan Press, 1976, p. 208. "Lumes" eran llamadas las fogatas.

30) Julio Caro Baroja, La estación del amor, p.142.

31) Sebastiá García Francisco Javier, Consideraciones estéticas sobre un arte efímero de Alicante: las hogueras de San Juan (1928-1987), Alicante, Instituto de estudios Juan Gil-Albert, 1988, p.13.

32) Victor Morla Asensio, El fuego en el Antiguo Testamento, Estudio de semántica lingüística, Valencia-Bilbao, Institución San Jerónimo, 1988, p.268.

33) Mircea Eliade, Herreros y alquimistas, p.97.

34) The HarperCollins Dictionary of Religion, Edi. Harper, San Francisco, 1995, p.362.

35) Mircea Eliade, Herreros y alquimistas, p.97.

36) Rodrigo Caro, Dias geniales o lúdicros, II, p.52-56. "lustro llamaban a un general sacrificio y expiración que hacían en Roma cada cinco años para expiar y limpiar la ciudad y sus vecinos, y de aquí vino a llamarse el espacio de cinco anos lustro".

37) José María Satrústegi, Mitos y creencias, p.89.

38) Recordemos que las notas musicales derivan de la primera estrofa del himno gregoriano

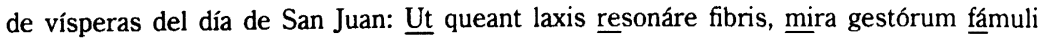
tuórum, solve pollúti lábii reátum, sancte Ioánnes.

39) Sebastiá García Francisco Javier, Consideraciones estéticas sobre un arte efímero de Alicante: las hogueras de San Juan (1928-1987), pp.91-92.

40) Luis Rivera Pérez, El fuego en las fiestas alicantinas, Alicante, Publicaciones del I.E.A., serie I, n. 38; 1977, p.104. 
41) Rodrigo Caro, Días geniales o lúdicros, II, pp.56-57.

42) Luis Agromayor, España en fiestas, Madrid, Aguilar, 1997, pp.269-271.

43) Julio Caro Baroja, Ritos y mitos equivocos, pp.113-115. El pasar descalzos por las brasas se hacía también en La Rioja según afirma mi madre.

44) Juan Garmendia Larranaga, Ritos de Solsticio de verano (1) Festividad de San Juan Bautista, Donostia, Kriselu, 1987, p.11. Podría estar relacionado esto con los alardes que este día hay en algunos pueblos: cofrades con arcabuces o escopetas arman gran ruido. Ver Julio Caro Baroja, La estación del amor, pp.263-272.

45) Kurt E. Schwighardt, Caminar sobre el fuego, Barcelona, Luciérnaga, 1995, p.78.

46) Mircea Eliade, Herreros y alquimistas, 1996, p.73.

47) Julio Caro Baroja, La estación del amor, p.144.

48) Juan Garmendia Larrañaga, Ritos de Solsticio de verano (1) Festividad de San Juan Bautista, Donostia, Kriselu, 1987, p.10.

49) José María Satrústegi, Mitos y creencias, p.62.

50) Mircea Eliade, El mito del eterno retorno, p.58.

51) Chucho Dorta "Benahuya" (Jesús Eustaquio Dorta Díaz), Sol, fuego, cabras y mar en las noches de San juam, La Laguna (Islas Canarias), Graficolor, 1992, pp.270-274.

52) José María Satrústegi, Mitos y creencias, p.86.

53) Enciclopedia Universal Ilustrada Espasa Calpe, Madrid, t. XXIV, 1984, p.1450.

54) Juan Garmendia Larrañaga, Ritos de Solsticio de verano (1) Festividad de San Juan Bautista, Donostia, Kriselu, 1987, pp.11-12.

55) Xosé Chao rego, O misterio do lume, Vigo, Sept, 1985, p.14.

56) Jose María Satrústegi, Mitos y creencias, p.88.

57) Julio Caro Baroja, La estación del amor, p.153.

58) José María Satrústegi, Mitos y creencias, pp.80-81.

59) Julio Caro Baroja, La estación del amor, p.144.

60) Julio Caro Baroja, La estación del amor, p.147.

61) Josep Maria Fericgla, "Fiestas de verano, origen y vigencia", Rev. GEO 103, 1995 (agosto), pp.70,73.

62) Nicolás Tenorio, La alde a gallega, Vigo, Xerais de Galicia, 1982, p.141.

63) Julio Caro Baroja, La estación del amor, p.152.

64) José María Satrústegi, Mitos y creencias, pp.79-80.

65) Julio Caro Baroja, La estación del amor, p.152.

66) José María Satrústegi, Mitos y creencias, pp.82-83.

67) Asahi Sinbun, 23 de junio de 1998, Japón. Hay una foto en color narrando esto.

68) Oscar Javier Mendoza García, “El gallo de Carnaval en España,"Hispánica 42, Tokio, 1998, 
pp.143-157. El gallo es símbolo de la vida, expulsor de la muerte, de los espíritus malignos, diablos, brujas, etc. en el folklore indogermano en general. Julio Caro, $\mathrm{El}$ Carnaval, Madrid, Taurus, 1979, p.89.

69) Ver la encadenación de elementos de las fiestas de San Juan con las fiestas de Mayo y con las fiestas de invierno y primavera en Julio Caro Baroja, La estación del amor, pp.297298.

\section{BIBLIOGRAFIA}

Caro Baroja, Julio. 1978. La estación del amor. Madrid: Taurus.

- 1989. Ritos y mitos equívocos. Madrid: Itsmo.

Caro, Rodrigo. 1978. Días geniales o lúdicros II. Madrid: Espasa-Calpe.

Chao Rego, Xosé. 1985. O misterio do lume. Vigo: Sept.

Costa, Juaquín. 1917. La religión de los celtiveros y su organización política y civil, t. XII de la Biblioteca económica 2a. edición. Madrid: Biblioteca Costa.

Dorta "Benahuya"Chucho (Jesús Eustaquio Dorta Díaz). 1992. Sol, fuego, cabras y mar en las noches de San juan. La Laguna (Islas Canarias): Graficolor.

Eliade, Mircea. 1995. El mito del eterno retorno. Madrid: Alianza Editorial.

- 1996. Herreros y alquimistas. Madrid: Alianza Editorial.

Frazer James. 1976. The Golden Bought. London: The Macmillan Press (1931).

Garmendia Larrañaga, Juan. 1987. Ritos de Solsticio de verano (1) Festividad de San Juan Bautista Donostia: Kriselu.

Gil Murcia, Pedro. 1992. El folklore de San Juan, costumbres y tradiciones. Madrid: Ayuntamiento de Alcobendas (Centro de Actividades Tradicionales de Alcobendas).

Kurt E. Schwighardt. 1995. Caminar sobre el fuego. Barcelona: Luciérnaga.

Menéndez Pelayo, Marcelino. 1980. Historia de los heterodoxos españoles, t. I.

Morla Asensio, Victor. 1988. El fuego en el Antiguo Testamento, Estudio de semántica lingüística. Valencia-Bilbao: Institución San Jerónimo.

Satrústegi, José María. 1983. Mitos y creencias, San Sebastián: Sendoa.

Sebastiá García Francisco Javier. 1988. Consideraciones estéticas sobre un arte efímero de Alicante: las hogueras de San Juan (1928-1987). Diputación Provincial de Alicante: Instituto de Estudios Juan Gil-Albert.

Sebastián de Cobarrubias Orozco. 1995. Tesoro de la lengua castellana o española (de 1611). Madrid: Castalia.

Tenorio, Nicolás. 1982. La alde a gallega, Vigo: Xerais de Galicia.

Yravedra, Luisa y Rubio, Esperanza. 1980. Leyendas y tradiciones de la Rioja Logroño: Instituto de estudios riojanos. 
〈Resumen〉

\section{Las hogueras de San Juan en el folklore español}

\section{Oscar Javier MENDOZA GARCIA}

Ritos de contenido naturalista subyacen bajo costumbres piadosas de significación religiosa por siglos al haberlos cristianizado la Iglesia. En el día de San Juan Bautista se siguen realizando en España las hogueras que los celtíveros heredan de los arios del Asia Central y con las que ya desde tiempos ancestrales se tiene en cuenta el poder vivificante del sol. Es la hierofanía del sol, el día de máximo esplendor, en que se opera una transformación del cosmos, una nueva creación que se manifiesta en ritos en que el sol es elemento clave que renueva, cura, limpia y protege. Esto lo vemos con ejemplos sobre todo del norte de España, de donde hay más datos. La preservación y curación de males (enfermedades de piel, brujas, tormentas, animales dañinos) y el asegurar una buena cosecha han sido los deseos y creencias que han perpetuado las hogueras en favor de la conservación de la vida y generación del hombre. Hoy, más que como diversión, se promueven en búsqueda de las propias raíces y en pro de la unidad y concordia de pueblos y ciudades que quieren mostrar su identidad. 